\title{
Comparative study of chest pain characteristics in patients with normal and abnormal coronary angiograms
}

\author{
R A Cooke, N Smeeton, J B Chambers
}

\begin{abstract}
Objective-To improve the characterisation of chest pain by comparing symptoms in patients with normal and abnormal coronary angiograms.
\end{abstract}

Study design-Prospective case-control study.

Setting-Single tertiary cardiac referral centre.

Patients- 65 consecutive patients with chest pain and completely normal coronary angiograms recruited over a period of one year, and 65 sex matched patients with significant stenoses at angiography.

Main outcome measures-Standardised chest pain questionnaires.

Results -61 of 65 patients (94\%) and every control reported chest pain on exertion. There were no important differences in the site, quality, and radiation of pain but three symptoms had discriminatory value expressed in binary fashion ("typical" $v$ "atypical"): the consistency with which pain was reproduced by exercise (typical, score index 10/10), the duration of pain episodes (typical, five minutes), and the frequency of pain at rest (typical, $10 \%$ all pain episodes). All three symptoms were atypical in 21 (32\%) patients with normal coronary angiograms, but only one patient with an abnormal coronary angiogram. Patients with no typical features had a $2 \%$ chance of an abnormal coronary angiogram if aged under 55 years or $12 \%$ if aged 55 years or more. The additional impact of exercise stress testing was low.

Conclusions-Chest pain characteristics which separate patients with normal coronary angiograms from patients with obstructive coronary heart disease can be defined objectively. This may allow improvements in referral patterns for specialist opinion or angiography, and in characterisation of patients in research studies.

(Heart 1997;78:142-146)

Keywords: characterisation of chest pain; coronary angiogram; ischaemic heart disease; non-cardiac chest pain

Chest pain is a complex symptom and its description is often simplified both in clinical practice and in research studies as either "typical" or "atypical" of a cardiac origin. These terms are subjective and open to wide variation in interpretation. For example Day and Sowton observed that 27 of their patients with normal coronary anatomy $(60 \%)$ had pain related to exertion, but in only seven $(16 \%)$ was the relation reproducible. ${ }^{1}$ It is not clear therefore whether the incidence of "typical" pain for this study was either $60 \%$ or $16 \%$, nor is it clear how we should define a reproducible relation to exercise. There are in fact few objective data about chest pain characteristics, and almost none comparing patients with normal and abnormal coronary angiograms.

The objective of this study therefore was to compare the symptoms in patients with normal and abnormal coronary angiograms and to define those characteristics most closely associated with a diagnosis of typical chest pain, based on angiographic findings.

\section{Methods}

SUBJECTS

Of 1022 patients undergoing coronary angiography for the investigation of chest pain between March 1990 and April 1991, 84 $(8 \cdot 2 \%)$ had completely normal coronary angiograms. Five patients had confirmed myocardial infarction, nine had left ventricular hypertrophy or abnormal regional wall motion on echocardiography, and three had mitral valve prolapse. In addition two patients had pain of recent onset (within the previous two months). There remained a study group of 65 patients. Their mean age was 54 (SD 9.0) years and $41(66 \%)$ were female (table 1). These were compared with 65 sex matched consecutive admissions, all of whom had an angiographically significant stenosis $(>70 \%$ luminal diameter narrowing by visual assessment) of at least one major epicardial artery subtending a normally contracting region of myocardium, and an estimated ejection fraction of $\geqslant 50 \%$ by visual assessment of the contrast ventriculogram. None had significant valve disease, previous myocardial infarction, or had been previously investigated by coronary angiography (table 1). The results of exercise treadmill testing were available for 55 patients with normal and for 56 patients with abnormal coronary angiograms (table 2 ).

\section{PROCEDURES}

Each patient was interviewed within 24 hours of coronary angiography by one of two authors who were unaware of the angiographic findings and clinical details. A standardised questionnaire modified from Master was used to 
Table 1 Demographic data

\begin{tabular}{|c|c|c|}
\hline & $\begin{array}{l}\text { Normal patients } \\
(n=65)\end{array}$ & $\begin{array}{l}\text { Abnormal patients } \\
(n=65)\end{array}$ \\
\hline $\begin{array}{l}\text { Age (mean) (SD) } \\
\text { Sex (No (\%) female) }\end{array}$ & $\begin{array}{l}53 \cdot 6(9 \cdot 0) \\
41(66 \%)\end{array}$ & $\begin{array}{l}61(8 \cdot 5)^{1} \\
41(66 \%)\end{array}$ \\
\hline Smoking: & & \\
\hline Never & $33(51 \%)$ & $22(34 \%)^{2}$ \\
\hline Current & $16(25 \%)$ & $23(35 \%)$ \\
\hline Cigarette years (median) (range) & $0(0-1400)$ & $245(0-1600)$ \\
\hline History of hypertension & $21(32 \%)$ & $28(43 \%)$ \\
\hline Blood pressure $>160 / 95 \mathrm{~mm} \mathrm{Hg}$ & $3(5 \%)$ & $22(34 \%)^{3}$ \\
\hline Family history of CAD & $27(42 \%)$ & $25(38 \%)$ \\
\hline Cholesterol $(\mathrm{mmol} / \mathrm{l})$ & $6 \cdot 0(1 \cdot 5)$ & $6 \cdot 8(1 \cdot 5)^{4}$ \\
\hline \multirow{2}{*}{\multicolumn{3}{|c|}{$\begin{array}{l}195 \% \text { confidence interval for the difference between the means is } 4.4 \text { to } 10.5, \mathrm{P}<0.01 \text {. } \\
{ }^{2} \chi^{2}=3.9, \mathrm{df}=2, \mathrm{P}>0.05 \text {. } \\
\text { 3 } \mathrm{P}<0.001 \text {. } \\
\text { }{ }^{2} \text { Data available for } 46 \text { patients with normal, and } 54 \text { patients with abnormal coronar } \\
\text { angiograms. The } 95 \% \text { confidence interval for the difference between the means is } 0.19 \text { to } 1.37 \\
P<0.01 \text {. } \\
\text { CAD, coronary artery disease. }\end{array}$}} \\
\hline & & \\
\hline \multicolumn{3}{|l|}{ Table 2 Exercise data } \\
\hline & $\begin{array}{l}\text { Normal patients } \\
(n=55)\end{array}$ & $\begin{array}{l}\text { Abnormal patients } \\
(n=56)\end{array}$ \\
\hline \multicolumn{3}{|l|}{ Heart rate (beats/min): } \\
\hline Rest & $85(15)$ & $74(13) \dagger$ \\
\hline Peak & $125(23)$ & $156(29) \dagger$ \\
\hline \multicolumn{3}{|l|}{ Systolic blood pressure $(\mathrm{mm} \mathrm{Hg})$ : } \\
\hline Rest & $132(18)$ & $154(24) \dagger$ \\
\hline Peak & $174(26)$ & $188(27)^{\star}$ \\
\hline Exercise time (min) & $6(2 \cdot 8)$ & $9(2 \cdot 7) \dagger$ \\
\hline Chest pain & $32(58 \%)$ & $41(73 \%)^{\star}$ \\
\hline \multicolumn{3}{|l|}{ ST depression: } \\
\hline$\geqslant 2 \mathrm{~mm}$ & $5(9 \%)$ & $23(41 \%)+$ \\
\hline LBBB & $3(5 \%)$ & $1(2 \%)$ \\
\hline
\end{tabular}

Data expressed as mean (SD). ${ }^{\star} \mathrm{P}<0.01 ;+\mathrm{P}<0.001$ (two tailed $t$ test).

LBBB, left bundle branch block.
Coronary angiography was performed using the standard Sones or Judkins techniques with multiple orthogonal views. All angiograms were reported by two experienced cardiologists. A normal angiogram was one where there was complete absence of even minimal luminal irregularities. A significant epicardial stenosis was defined as a luminal diameter narrowing of $70 \%$ or more by visual assessment. Left ventricular function was assessed visually by contrast ventriculography, and in addition echocardiography was performed in each patient.

\section{STATISTICS}

Values are given as mean (SD). The Student $t$ test (two tailed) or the Mann Whitney U test were used where appropriate for continuous variables, and the $\chi^{2}$ test with Yates correction or Fisher exact test was used for categorical variables. A P value less than 0.05 was considered to be significant. To investigate the ability of the data to predict the presence of coronary artery disease, logit analysis was performed (using the statistical package for the social sciences version $\mathrm{X}$ (SPSS-X)). A linear model was fitted to the log of the odds of an individual being diagnosed as having coronary artery disease based on the independent variables which were viewed as having two categories. Multiple variables including the questions relating to symptoms, age, and gender were entered The possible first and second order interactions between independent variables were studied. The post-test probability of disease was calculated according to the method described by Diamond and Forrester. ${ }^{4}$ tions about the site, quality, radiation, precipitating and relieving factors, and duration of pain. The consistency with which pain was reproduced by exercise was tested by asking the patient "if you go up a steep hill (or any other appropriate stressor) on 10 separate occasions, on how many of these would you experience chest pain?" The response was called the reproducibility score (range 0-10). The frequency of spontaneous rest pain was documented by asking "if you have 10 episodes of pain in a row, how many occur sitting quietly?" Patients were also asked to specify, where possible, the usual duration and range in duration of their pain episodes. A second questionnaire was used to record the incidence of associated symptoms. This included four questions from the British Thoracic Society dyspnoea index, 10 used in previous work by one of the authors to screen for organic or psychogenic breathlessness, and 12 relating to the upper and lower gastrointestinal tract. $^{3}$

A standard Bruce protocol was used for exercise testing. All cardiac medication was stopped a minimum of 48 hours before the test. Significant ST segment depression was defined as horizontal or downsloping ST segment depression of at least $1 \mathrm{mV}$ in any lead occurring over three consecutive beats. The electrocardiograms were reported by an experienced independent blinded observer. A positive test was defined by the development of significant ST depression or left bundle branch block.

\section{Results}

\section{CHEST PAIN CHARACTERISTICS}

There were no important differences between the groups in the site, radiation, or quality of pain (table 3 ). The median duration of symptoms was 24 months (range 2 to 216 ) in patients with normal coronary angiograms, $v$ 18 months (range 2 to 720 ) in patients with abnormal coronary angiograms $(P>0.05)$. Thirty five $(54 \%)$ and $53(81 \%)$ patients respectively had daily pain (odds ratio $0 \cdot 26$, $P<0.01$ ).

Sixty one patients with normal coronary angiograms (94\%), and every patient with an abnormal coronary angiogram, reported provocation of chest pain by physical activity, but a consistent relation with physical activity (reproducibility score 10) was found in only $25(38 \%)$ and $51(78 \%)$ patients, respectively (odds ratio $0.17, P<0.001$ ). Pain provoked by emotional stress was equally common (44 (68\%) and $34(52 \%)$ patients; $P>0.05)$. Pain in relation to meals occurred in six patients also in 16 patients with abnormal angiograms (26\%) (odds ratio $0.31, P<0.05$ ). Seven patients with normal angiograms (11\%) and 14 patients with abnormal angiograms $(22 \%)$ reported pain on lying flat $(P>0.05)$.

Fifty four patients with normal coronary angiograms $(83 \%)$, but only 35 patients with with normal coronary angiograms $(9 \%)$, but 
Table 3 Chest pain characteristics

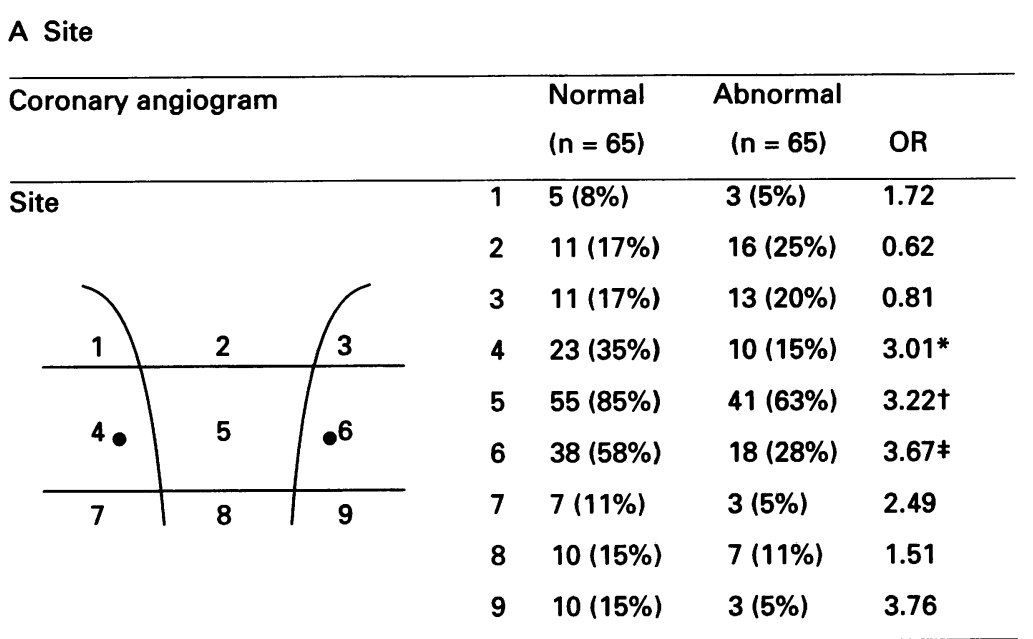

*P $<0.05+P<0.01 \neq P<0.001$

B Radiation and quality

\begin{tabular}{lllll}
\hline Coronary angiogram & $\begin{array}{c}\text { Normal } \\
\text { (n =65) }\end{array}$ & $\begin{array}{c}\text { Abnormal } \\
(\mathrm{n}=65)\end{array}$ & OR \\
\hline Radiation: & Back & $19(29 \%)$ & $20(31 \%)$ & 0.93 \\
& Neck & $28(43 \%)$ & $29(45 \%)$ & 0.94 \\
& Left arm & $34(52 \%)$ & $34(52 \%)$ & 1.0 \\
& Right arm & $17(26 \%)$ & $17(26 \%)$ & 1.0 \\
& & & & \\
Quality: & Gripping & $28(43 \%)$ & $28(43 \%)$ & 1.0 \\
& Stabbing & $8(12 \%)$ & $9(14 \%)$ & 0.87 \\
& Burning & $4(6 \%)$ & $14(22 \%)$ & $0.24 *$ \\
\hline
\end{tabular}

*P $<0.05$

OR, odds ratio

abnormal angiograms (54\%) reported episodes of unprovoked pain at rest (odds ratio $4.2, P<0.001)$. These accounted for more than one in 10 pain episodes in 46 patients with normal coronary angiograms (71\%), compared to only 19 patients with abnormal angiograms (29\%) (odds ratio 5.9, $P<0.001)$. The incidence of nocturnal pain was similar $(18(28) \% v 11(17) \%$ of patients, $P>0.05)$.

Table 4 Breathlessness questionnaire

\begin{tabular}{llll}
\hline & $\begin{array}{l}\text { Normal patients } \\
(n=65)\end{array}$ & $\begin{array}{l}\text { Abnormal patients } \\
(n=65)\end{array}$ & OR \\
\hline Dyspnoea: & $37(57 \%)$ & $25(38 \%)$ & \\
Walking on the flat & $49(75 \%)$ & $38(58 \%)$ & $2 \cdot 11$ \\
Stairs & $42(65 \%)$ & $31(48 \%)$ & $2 \cdot 18$ \\
Stops due to dyspnoea & $21(32 \%)$ & $16(25 \%)$ & $2 \cdot 0$ \\
Washing or dressing & $17(26 \%)$ & $7(11 \%)$ & $1 \cdot 46$ \\
Rest & $26(40 \%)$ & $15(23 \%)$ & $2 \cdot 93^{\star}$ \\
Conversation & $23(35 \%)$ & $5(8 \%)$ & $6 \cdot 57 \ddagger$ \\
Trivial exertion & $38(58 \%)$ & $19(29 \%)$ & $3 \cdot 41 \dagger$ \\
Emotion & $10(15 \%)$ & $3(5 \%)$ & $3 \cdot 76$ \\
Situational & $22(34 \%)$ & $11(17 \%)$ & $2 \cdot 51^{\star}$ \\
Sudden episodes & $13(20 \%)$ & $7(11 \%)$ & $2 \cdot 07$ \\
Lying flat & $45(69 \%)$ & $25(38 \%)$ & $3 \cdot 60 \ddagger$ \\
Air hunger & $32(49 \%)$ & $17(26 \%)$ & $2 \cdot 74 \dagger$ \\
Light headedness & $34(52 \%)$ & $14(22 \%)$ & $4 \cdot 0 \ddagger$ \\
Digital paraesthesiae & & & \\
\hline
\end{tabular}

${ }^{\star} \mathrm{P}<0.05 ; \dagger \mathrm{P}<0.01 ; \ddagger \mathrm{P}<0.001$.

$O R$, odds ratio.
There was no significant difference between the groups in the numbers reporting relief by short acting nitrates: 46 patients with normal coronary angiograms $(71 \%) v 48$ patients with abnormal angiograms (74\%). However, relief within five minutes occurred in only 19 patients $(29 \%)$ and 41 patients $(63 \%)$ respectively (odds ratio $0.24, P<0.001$ ). No relief was reported by 15 patients with normal coronary angiograms (23\%), and 10 patients with abnormal angiograms (15\%), $P>0.05$.

The duration of pain episodes was five minutes or less in 23 patients with normal coronary angiograms (35\%), compared with 56 patients with abnormal angiograms (86\%) (odds ratio $0.09, \mathrm{P}<0.001$ ); pain lasting longer than 30 minutes was reported by nine $(14 \%)$ and none, respectively $(P<0.01)$. Fifteen patients with normal angiograms (23\%) and three with abnormal angiograms (5\%) could not specify the duration of pain (odds ratio $6.2, \mathrm{P}<0.01$ ).

\section{Associated symptoms}

The median (range) number of symptoms of breathlessness was significantly higher in patients with normal coronary angiograms than in patients with abnormal angiograms, at 5.0 (0 to 11$) v 3.0$ (0 to 10$), \mathrm{P}<0.001$ (table 4).

Thirteen patients with normal coronary angiograms $(20 \%)$ and three with abnormal angiograms $(5 \%)$ had intermittent dysphagia (odds ratio $5 \cdot 2, \mathrm{P}<0.05$ ), and $14(22 \%)$ and two $(3 \%)$ respectively had variable stool habit (odds ratio 8.6, $\mathrm{P}<0.01$ ). There were no significant differences in the incidence of heartburn (24 (37\%) v $25(38 \%))$, waterbrash (20 $(31 \%) v 19(29 \%))$, or flatulence $(29(45 \%) v$ $20(31 \%))$.

Twenty patients with normal coronary angiograms $(31 \%)$ and 16 with abnormal angiograms $(25 \%)$ reported chest wall tenderness ( $P>0.05)$; pain was precipitated by neck or back movement in only four $(6 \%)$ and none, respectively. Five patients $(7 \%)$ and two patients $(3 \%)$, respectively, localised their pain using one finger.

Differentiating patients with normal and abnormal coronary angiograms

Only three symptom variables were of statistical value in separating the groups: the reproducibility score; the rest score; and the usual duration of pain episodes (table 5). These were expressed in binary fashion, where a reproducibility score of 10 , a rest score of 0 or 1 , and usual duration of five minutes were defined statistically as "typical", and a reproducibility score of 1 to 9 , rest score of 2 to 10 , and usual duration more than five minutes were defined as "atypical" or likely to be associated with a normal coronary angiogram. The best separation of the groups was obtained using two or more "typical" features as a cut off (table 6) and these were present in only 16 patients with normal coronary angiograms (26\%), but in 55 patients with abnormal coronary angiograms $(85 \%)$. 
Table 5 Logit model for the prediction of normal $v$ abnormal coronary angiogram

\begin{tabular}{llll}
\hline & Coefficient & $Z$ value & $S E$ \\
\hline Constant & $0 \cdot 28$ & $2 \cdot 12$ & $0 \cdot 13$ \\
Age (55 years $v<55$ years) & 0.47 & 3.69 & 0.13 \\
Reproducibility score $(10 v 1-9)$ & 0.47 & 3.60 & 0.13 \\
Usual duration $(5$ min $v>5$ min) & 0.42 & 3.36 & 0.13 \\
Rest score (0 or 1 $2-10)$ & 0.26 & $2 \cdot 21$ & 0.12 \\
\hline
\end{tabular}

Only subjects with exertional chest pain (61/65 patients with normal angiogram, and every patient with abnormal angiogram) were entered into the analysis. None of the interactions fitte in the logit model was significant, and the level of agreement between the estimated probabilities and the observed incidence of normal angiograms was high $(P=0.68)$.

Twenty patients with abnormal angiograms (30\%) had involvement of only a single vessel, 29 (45\%) pad $(45 \%)$ had two vessel disease, and $16(25 \%)$ three vessel disease. Using the Kruskal Wallis on way analysis of variance there was no correlation with the number of diseased vessels for the reproducibility of pain $(H=0.32(2) ; P=0.85)$, the duration of pain episod
$0.46)$, or the frequency of unprovoked rest pain $H=1.69(2) ; P=0.43)$.

Table 6 Cumulative frequencies of "typical" pain features in patients with normal and abnormal coronary angiograms

\begin{tabular}{lll}
\hline Number of "typical" features* & $\begin{array}{l}\text { Normal patients } \\
(n=61)\end{array}$ & $\begin{array}{l}\text { Abnormal patients } \\
(n=65)\end{array}$ \\
\hline One & $43(70 \%)(9 / 35)$ & $64(99 \%)(38 / 56)$ \\
Two & $16(26 \%)(2 / 15)$ & $55(85 \%)(35 / 47)$ \\
Three & $7(12 \%)(1 / 7)$ & $29(48 \%)(20 / 26)$ \\
\hline
\end{tabular}

${ }^{\star}$ Number of subjects (\%) followed by the incidence of ECG abnormalities (ST depression or lef bundle branch block on exercise) in parentheses.

Table 7 Probability of abnormal coronary angiogram (CA) based on pain characteristics and age

\begin{tabular}{llc}
\hline No of "typical" symptoms & $\begin{array}{l}\text { Probability (\%) of } \\
\text { abnormal } C A\end{array}$ & Actual incidence \\
\hline$<55$ years: & & \\
$0 / 3$ & $2 \%$ & $14 / 14(100 \%)$ \\
$1 / 3$ & $6 \%$ to $12 \%$ & $2 / 15(13 \%)$ \\
$2 / 3$ & $25 \%$ to $44 \%$ & $5 / 11(45 \%)$ \\
$3 / 3$ & $69 \%$ & $6 / 11(55 \%)$ \\
$\geqslant 55$ years: & $12 \%$ & $1 / 8(13 \%)$ \\
$0 / 3$ & $29 \%$ to $48 \%$ & $7 / 21(33 \%)$ \\
$1 / 3$ & $69 \%$ to $84 \%$ & $22 / 26(85 \%)$ \\
$2 / 3$ & $93 \%$ & $22 / 24(92 \%)$ \\
$3 / 3$ & & \\
\hline
\end{tabular}

Table 8 The additional value of exercise testing: pre and post-test probabilities of abnormal coronary angiogram

\begin{tabular}{|c|c|c|c|c|c|}
\hline \multirow{2}{*}{$\begin{array}{l}\text { Pre-test } \\
\text { probability }\end{array}$} & \multicolumn{2}{|c|}{ Positive test } & \multirow{2}{*}{$\begin{array}{l}\text { Predictive } \\
\text { value }\end{array}$} & \multicolumn{2}{|c|}{ Post-test probability } \\
\hline & $N C A$ & $A C A$ & & Positive test & Negative test \\
\hline $\begin{array}{l}\text { Low } \\
\text { High }\end{array}$ & $\begin{array}{c}10 / 33 \\
0 / 3\end{array}$ & $\begin{array}{c}3 / 6 \\
24 / 33\end{array}$ & $\begin{array}{l}65 \% \\
75 \%\end{array}$ & $\begin{array}{l}16 \% \\
51 \%\end{array}$ & $\begin{array}{l}54 \% \\
86 \%\end{array}$ \\
\hline
\end{tabular}

NCA, normal coronary angiogram; ACA, abnormal coronary angiogram. In this analysis the conventional $30 \%$ or less probability of having an abnormal coronary angiogram is taken as low, and $70 \%$ or more as high probability.

The overall results of the logit regression analysis are shown in table 7 . In addition to the three symptom variables above, age $\geqslant 55$ years or $<55$ years was statistically significant. Chest pain which was exertional but included none of the "typical" features relating to reproducibility, frequency of rest pain, and duration was associated with a probability of obstructive disease of only $2 \%$ in patients aged $<55$ years, and $12 \%$ for those aged $\geqslant 55$ years. A positive exercise test result increased the probability of disease from $2 \%$ to $5 \%$ in patients $<55$ years, and from $12 \%$ to $33 \%$ in patients $\geqslant 55$ years. The respective probabilities of disease in patients with normal test results were $<1 \%$ and $5 \%$.

The additional value of exercise treadmill testing for the prediction of an abnormal coronary angiogram is shown in table 8.

\section{Discussion}

Too much emphasis is attached to the quality, site, and radiation of pain and not enough importance given to the consistency with which pain is related to exercise and its duration. By concentrating on the latter-even in this selected group of patients-a detailed history resulted in a useful separation of those with normal and abnormal coronary angiograms.

Waxler et al reported "typical" pain in only nine of 100 patients (all female) with angiographically normal coronary arteries (9\%). ${ }^{5}$ Similarly Proudfit et $a l^{6}$ and Day and Sowton ${ }^{1}$ stated that in the majority of patients the history was "atypical". These studies, however, were retrospective and no comparison was made against patients with angiographically confirmed angina. Furthermore, the criteria used to define typical pain were subjective and largely ill defined. Alban Davies et al examined 70 consecutive admissions with suspected angina, of whom 52 had myocardial ischaemia and the remainder had oesophageal disease. ${ }^{7}$ Discriminant analysis identified eight features of value, including the duration of pain episodes, consistency of provocation by exercise, and frequency of spontaneous pain. The observations are consistent with our findings but the study involved acute emergency admissions and there was no angiographic confirmation of clinical diagnoses.

The separation of patients into those with typical and atypical pain is arbitrary and may be too simplistic since it is apparent that there are various degrees of "typical". The three point questionnaire model in our study could be used to divide pain into at least four categories depending on whether no answers, one answer, two answers, or all the answers were typical. If none was typical and the patient was aged $<55$ years, the chance of an abnormal coronary angiogram was $2 \%$, and if one, two, or three were typical the probabilities ranged from $6 \%$ to $69 \%$ (table 7 ). If confirmed by further work, such a clinical classification could guide specialist referral by a general practitioner or help a cardiologist decide the need for angiography. Thus in retrospect if angiography had not been performed in patients in whom all pain characteristics were atypical, approximately one third of all normal angiograms would have been avoided at the cost of failing to detect one patient with obstructive coronary disease.

The present study makes no implications about the aetiology of chest pain in patients with normal coronary angiograms. It has long been recognised that the history in patients with syndrome $\mathrm{X}$ often includes many atypical features. ${ }^{8}$ In a study of patients referred to a specialist pain clinic Kaski et al reported that most had pain which was typical for angina but noted that more than half had episodes of pain which usually lasted longer than 10 minutes, and over a third had pain at rest. ${ }^{9}$ In our study the incidence of syndrome $X$ as strictly defined was very low. Comparisons with other published work may be facilitated by the use of a standard classification of pain such as the one described in our study.

There was a low discriminatory power of symptoms often thought to identify patients 
with non-cardiac pain. Pain in relation to meals or provoked by bending or stooping suggesting a gastro-oesophageal aetiology was less common in patients with normal as compared to abnormal coronary angiograms, and pain radiation to the back-which was found by Schofield et al to be associated with oesophageal rather than cardiac pain-was equally common. ${ }^{10}$ Similarly there were no differences in the incidence of localised chest wall tenderness and localisation "under a finger", thought to suggest musculoskeletal pain. These symptoms may not be taken in isolation and should be interpreted in the overall context. Of great importance was the fact that both groups reported relief of pain with short acting nitrates. However, rapid relief compatible with the pharmacological action of the drug was far more frequently seen in patients with abnormal coronary angiograms.

Symptoms of intermittent dysphagia and irregular bowel habit, consistent with a higher incidence of functional motility disorders or increased somatic awareness, were significantly more common in patients with normal than with abnormal angiograms. Most striking was the significantly higher incidence of breathlessness, but a considerable overlap between the groups prevented these from being of value in discrimination.

It was not the objective of the study to provide a prospective model for the prediction of angiographic results. It is recognised that the performance of discriminant statistical analysis when applied to the original data set is better than would be obtained with another series of patients. Further studies are warranted in larger and more diverse populations. It should also be noted that our data do not apply to patients with recent onset of pain, whose symptoms may be more atypical. It is also recog- nised that the present population is highly selected and that other criteria are likely to assume discriminative value in the wider clinical setting. Even in this highly selected patient group, however, an important degree of discrimination was obtained.

In conclusion, chest pain characteristics vary between patients with normal and abnormal coronary angiograms. A three point questionnaire defining the consistency with which pain is related to exercise and its duration differentiated accurately a high proportion of cases and may be the basis of a more objective classification of chest pain. This could be used to screen patients for referral to a cardiologist or for angiography.

1 Day LJ, Sowton E. Clinical features and follow up of patients with angina and normal coronary arteries. Lancet 1976;ii:334-7.

2 Master AM. The spectrum of anginal and non cardiac pain. ҰAMA 1964;187:894-9.

3 Chambers JB, Kiff PJ, Gardner WN, Jackson G, Bass C. Value of measuring end tidal pressure of carbon dioxide as an adjunct to treadmill exercise testing. $B M \mathcal{F} 1988$; as an adjun $296: 1281-5$.

4 Diamond GA, Forrester JS. Analysis of probability as an aid in the clinical diagnosis of coronary artery disease. $N$ Engl F Med 1979;300:1350-8.

5 Waxler EB, Kimbiris D, Dreifus LS. The fate of women with normal coronary arteriograms and chest pain resembling angina pectoris. Am $\mathcal{f}$ Cardiol 1971;28:25-32.

6 Proudfit WL, Shirey EK, Sones FM. Selective cine coronary arteriography: correlation with clinical findings in 1000 patients. Circulation 1966;33:901-10.

7 Alban Davies H, Jones DB, Rhodes J, Newcombe RG. Angina-like chest oesophageal chest pain: differentiation from cardiac pain by history. $₹$ Clin Gastroenterol 1985;7: from car

8 Kemp HG, Vokonas PS, Cohn PF, Gorlin R. The anginal syndrome associated with normal coronary arteriograms. syndrome associated with normal coronary arteriograms. R35-42.

9 Kaski JC, Rosano GM, Collins P, Nihoyannopoulos P Maseri A, Poole-Wilson PA. Cardiac syndrome X: clinical characteristics and left ventricular function. Long term follow up study. 7 Am Coll Cardiol 1995;25:807-14.

10 Schofield PM, Whorwell PJ, Jones PE, Brooks NH, Bennett DH. Differentiation of oesophageal and cardiac chest pain. Am $\mathcal{F}$ Cardiol 1988;62:315-16. 